\title{
Ecological Sustainability Assessment of Crop Rotations in Buenos Aires (Argentina)
}

\author{
Silvina Golik ${ }^{1}$, Adriana M Chamorro ${ }^{1}$, Rodolfo Bezus ${ }^{1}$, Andrea Pellegrini ${ }^{1}$, Bárbara Novillo ${ }^{1,2}$ and Axel Voisin $^{1,2}$ \\ ${ }^{1}$ Faculty of Agricultural and Forestry Sciences, UNLP, Argentina
}

${ }^{2}$ Scientific Research Commission, Province of Buenos Aires, Argentina

*Corresponding author: Silvina Golik, Faculty of Agricultural and Forestry Sciences, UNLP, Argentina

\begin{abstract}
A trial was carried out with the objective of comparatively evaluating the ecological sustainability of four crop rotations under two managements. The rotations were:

a. Oats/Soybeans 2o--Corn-Sunflower-Wheat,

b. Barley/Soybeans 2--Corn-Soybeans-Wheat,

c. Oilseed rape/Soybeans $2^{\circ}-$-Corn-Sorghum-Wheat and

d. Wheat/Soybeans 2o-Corn-Soybeans-Wheat.

The analyzed management were two: one is the "average management", the other is a "management of greater use of inputs". For the evaluation, five indicators were used: nutrient balance, contribution to soil organic matter, pesticide use impact, energy efficiency and water use efficiency. The rotation 2 was the one of greater sustainability under the two managements. The management of greater application of inputs improved sustainability mainly through better balance of nutrients despite reducing energy efficiency. It is considered important to evaluate the other dimensions of sustainability.
\end{abstract}

\section{Introduction}

Agricultural production in Argentina has suffered major changes in recent decades associated with the large increase in the area sowed with soybeans (Glycine $\max$ (L.) Merr) and its production model. These changes led to increasing environmental deterioration, economic concentration, social exclusion and loss of food sovereignty. In the northwest of the province of Buenos Aires, the spread of soybeans is more recent. In order to avoid or minimize the environmental and social problems associated with soybeans monoculture, it is necessary to generate local information that allows to include this crop more rationally in zonal production schemes and, at the same time, to diversify agricultural production through the inclusion of different crops, including oats (Avena sativa L.), barley (Hordeum distichum L.), oilseed rape (Brassica napus L.), wheat (Triticum aestivum L.), corn (Zea mays L.), sunflower (Helianthus annuus L.) and sorghum (Sorghum bicolor L. (Moench)). With this objective, trials were begun in La Plata for evaluating agricultural rotations of four years duration. These rotations were conducted under two types of management identified in the area through interviews with farmers and technicians in the area. Based on a definition of sustainable agriculture such as that which allows a flow of goods and services to be maintained over time that meet the socio-economic and cultural needs of the population, within the biophysical limits established by the proper functioning of natural systems (agro-ecosystems) that support it, this work evaluated, in comparative terms, the ecological sustainability of four agricultural rotations produced under two managements in La Plata (province of Buenos Aires) through different biophysical indicators.

\section{Materials and Methods}

Field trial was initiated in the 2011-12 in Buenos Aires (Argentina), in the Experimental Station Julio Hirschhorn (34은 S, 57 $57^{\prime} \mathrm{W}$ ), whose treatments were four crop rotations with two managements. The rotations were:
a. Oats/Soybeans $2^{\circ}$ - Corn - Sunflower - Wheat,
b. Barley/Soybeans $2^{\circ}$ - Corn - Soybeans - Wheat,
c. Oilseed rape/Soybeans $2^{\circ}$ - Corn - Sorghum - Wheat, and 


\section{d. Wheat/Soybeans $2^{\circ}$ - Corn - Soybeans - Wheat.}

The managements analyzed were two: one is used by the most of the farmers in the area, identified as "average management", the other is a "management of greater use of inputs", which is implemented by a smaller number of farmers, characterized by usually obtaining higher yields, and by applying a greater amount of inputs to their crops, mainly in the form of fertilizers. Five indicators were used to assess ecological sustainability: two related to soil quality (nutrient balance and soil organic matter contribution) as the basis of agricultural production, one related to biodiversity (impact of pesticide use) and two related to two other important resources for agro-ecosystems, energy (energy efficiency) and water (water use efficiency). The nutrient balance (NB) was calculated for N, P and S. The indicator used was the percentage of nutrient restitution. The index "soil organic matter contribution" (SOMC) was calculated as the dry matter contributed by each stubble crop multiplied by the value of the carbon: nitrogen ratio corresponding to each divided by 100 considering, therefore, as a dimensionless indicator. To evaluate the risk associated with the use of pesticides, the "Environmental impact quotient" (EIQ), developed by Kovach et al. [1], was used.

Energy efficiency (EE) was calculated as the relationship between energy output as yield for each crop and rotation and the energy input necessary for its production, including direct energy (fuel) and indirect energy associated with the manufacturing of inputs used. The water use efficiency (WUE) was calculated as the ratio between the yield of each crop in the rotation and the rainfall occurred during the fallow and their cycle. Data were processed by analysis of variance using the Tukey test $(\mathrm{P}<0.05)$ for the separation of means. The indicators were standardized, establishing five classes based on the range of values obtained in the trial. In all cases the highest value was assigned to the most desirable situation. To compare rotations and management, the Sustainability Index (SI) was calculated as the weighted average of the indicators once standardized: the local impact of agricultural practices was considered more important, so it was weighted with greater weight to the EIQ, the NB and the SOMC, than to the EE and the WUE. The calculation formula was: $\mathrm{SI}=\left[\left(\mathrm{EIQ}^{*} 2\right)+(\mathrm{NB} * 2)+\right.$ $\left.\left(\mathrm{SOMC}^{*} 2\right)+\mathrm{EE}+\mathrm{WUE}\right] / 8$.

\section{Results and Discussion}

Table 1. Total grain yield and indicators values used by the ecological sustainability assessment for four crop rotations in La Plata (Buenos Aires) produced under two managements. P value for ANOVA of each indicator.

\begin{tabular}{|c|c|c|c|c|c|c|}
\hline Rotation & $\begin{array}{l}\text { Total grain yield } \\
\text { (Kg.ha-1) }\end{array}$ & $\begin{array}{c}\text { EE } \\
\text { (MJ output. } \\
\text { MJ input-1) }\end{array}$ & EIQ & $\begin{array}{c}\text { WUE } \\
\text { (kg.ha-1.mm-1) }\end{array}$ & $\begin{array}{l}\text { NB } \\
\text { (\%) }\end{array}$ & SOMC \\
\hline \multicolumn{7}{|c|}{ Average management } \\
\hline 1 & 24348 & 13.38 & 320.1 & 7.35 & 26.7 & 3038 \\
\hline 2 & 31913 & 14.8 & 287.9 & 9.38 & 26.3 & 3414 \\
\hline 3 & 25633 & 13.33 & 391.4 & 7.35 & 25.7 & 3500 \\
\hline 4 & 28214 & 13.2 & 309.1 & 8.3 & 26.6 & 3384 \\
\hline \multicolumn{7}{|c|}{ Greater use input management } \\
\hline 1 & 28230 & 12.65 & 320.1 & 8.55 & 32.1 & 3703 \\
\hline 2 & 35512 & 14.43 & 287.9 & 9.8 & 32.9 & 3422 \\
\hline 3 & 27110 & 11.63 & 391.4 & 7.75 & 39.6 & 3887 \\
\hline 4 & 29711 & 12.38 & 309.1 & 8.73 & 29.1 & 3543 \\
\hline Rotation & $\mathrm{P}=0.0000$ & $\mathrm{P}=0.0041$ & not applicable & $\mathrm{P}=0.0000$ & $\mathrm{P}=0.0022$ & $\mathrm{P}=0.2326$ \\
\hline Management & $\mathrm{P}=0.0148$ & $\mathrm{P}=0.0007$ & not applicable & $\mathrm{P}=0.0122$ & $\mathrm{P}=0.0000$ & $\mathrm{P}=0.0152$ \\
\hline Rot x Man & $\mathrm{P}=0.4088$ & $\mathrm{P}=0.6047$ & not applicable & $\mathrm{P}=0.5240$ & $\mathrm{P}=0.0002$ & $\mathrm{P}=0.2335$ \\
\hline
\end{tabular}

Table 2. Sustainability index for four crop rotations in La Plata (Buenos Aires), produced under two managements.

\begin{tabular}{|c|c|c|c|}
\hline & Rotation 1 & Rotation 2 & Rotation 3 \\
\hline Average management & 1 & 2.5 & 0.75 \\
\hline Greater inputs use management & 2.38 & 2.63 & 2 \\
\hline
\end{tabular}




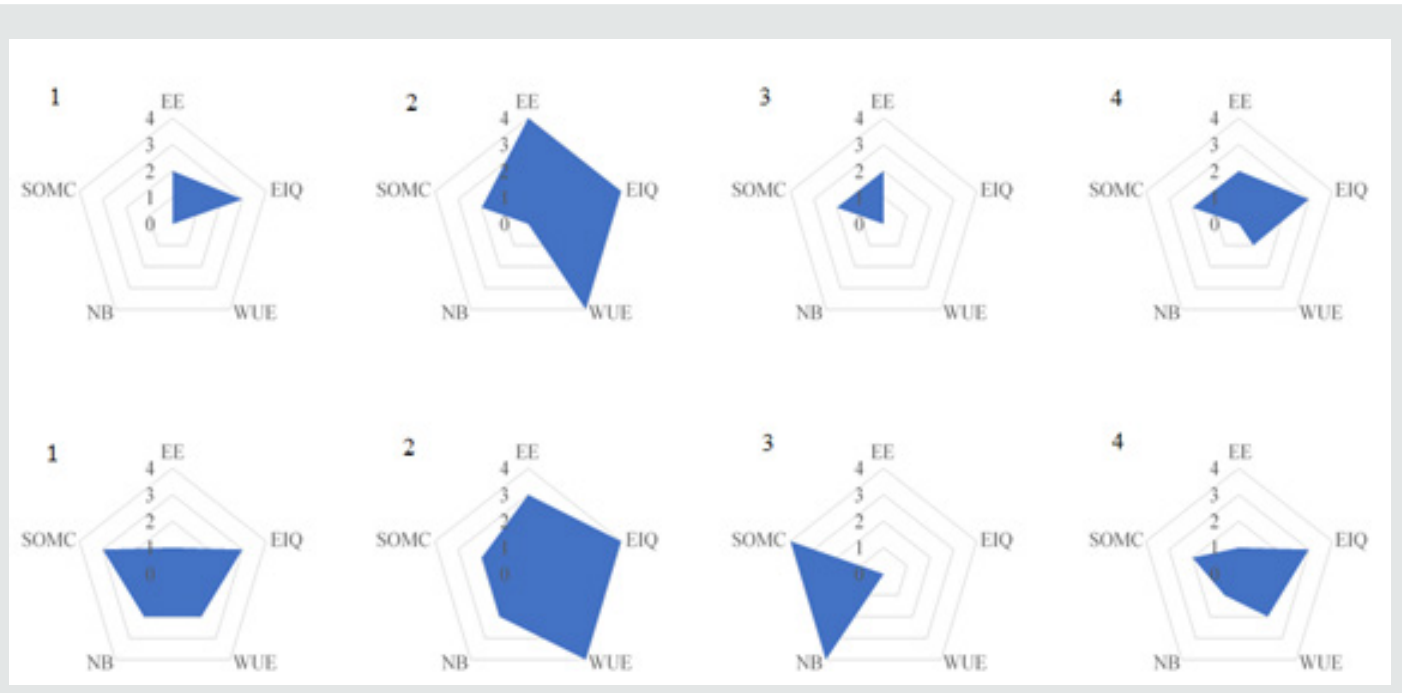

Figure 1:Graphical representation of five ecological sustainability indicators for four crop rotations produced under the average management (above) and under the higher use inputs management (below).

Total grain yield for each rotation under the two managements, mean value for indicators and its $\mathrm{P}$ value for the ANOVA are shown in Table 1. The EIQ was not processed by ANOVA because pesticide applications did not differ between managements but only among rotations. Yields and indicators were different between managements and rotations had different EE, WUE and NB. The last, moreover, registered Rotation x Management interaction. Rotations also obtained different values of EIQ. Indicators standardization allowed compare rotations (Figure 1). Rotation 2 reached the highest values for the most of indicators under both managements. Rotations 1 and 3 obtained the lowest values under the average management, and rotations 3 and 4 did this under the management of greater input use. All rotations improved NB with the greater input use but only some of these obtained better WUE and/or SOMC. EE was reduced when input use was greater in the four rotations. The SI showed rotation 2 as the most sustainable Table 2. This was consequence of a better use of energy and water, a lower impact of pesticide uses and a good contribution to the soil organic matter (Figure 1). These effects were observed in all crop's component of the rotations, included soybean $2^{\circ}$, corn and wheat (data not shown).

These crops were common for the four rotations, so these results suggest some advantage in the rotation design related to the "antecessor effect". On the other hand, rotation 3 was the least sustainable under both management due to its low EE and
WUE, that was verified in oilseed rape and soybean $2^{\circ}$ (data not shown) and the high impact of pesticide use, mainly in sorghum (data not shown). The higher sustainability of the greater input use management was not expected. Maybe it was related with the financial rationality of productor. In the average management, sustainability was low mainly due to the low restitution of nutrients. Under the other management, fertilizer doses did not much higher, the highest registered value was 39.6\%, but produced improvements in other indicators related with the higher yield and dry matter produced (WUE and/or SOMC) that made more sustainable this management. Different ecological sustainability of agricultural rotations suggests the importance of its assessment prior to implement changes in agricultural plans. The impact of management on the sustainability, that unexpectedly improved with the greater input use (mainly as fertilizers) indicates significant short comings in current crop management in the area related with the ecological dimension of the sustainability, but at the same time the need of look for alternatives for improve it through ways that not affect other production resources such us energy. At the same time, there is a need to deepen this analysis and move forward the assessment of the economic and socio-cultural dimensions of sustainability.

\section{References}

1. Kovach J, Petzoldt C, Degni J, Tette J (1992) A method to measure the environmental impact of pesticides. Disponible. 
(c) This work is licensed under Creative

To Submit Your Article Click Here: Submit Article

DOI: 10.32474/CIACR.2019.07.000268

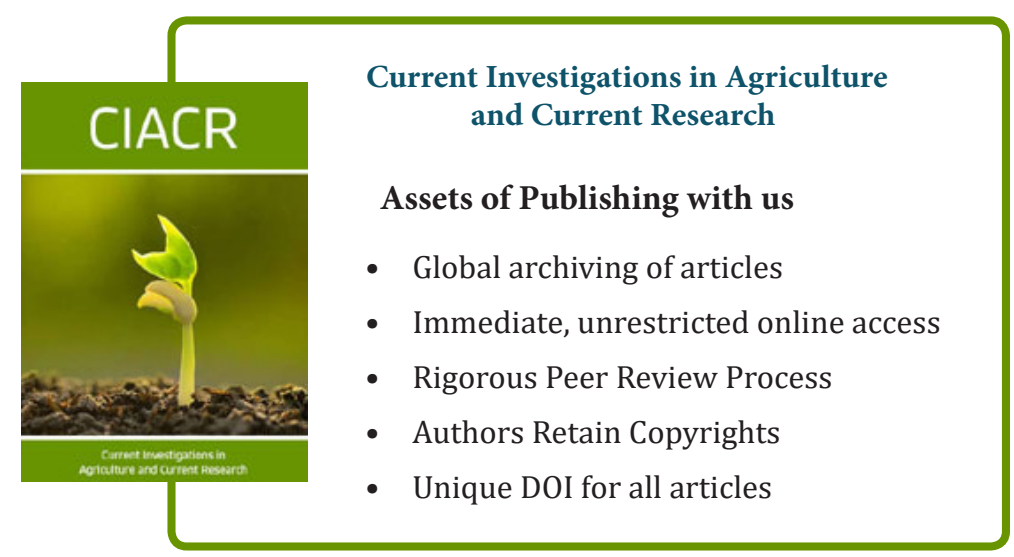

